\title{
Plutarco, dos Vidas, tres oradores: Foción, Demóstenes y Démades
}

\author{
Carlos Alcalde Martín ${ }^{1}$
}

Recibido: 12 de febrero de 2016 / Aceptado: 28 de diciembre de 2016

Resumen. En este artículo se analizan las figuras de tres oradores, Foción, Demóstenes y Démades, en las biografías que Plutarco dedicó a los dos primeros. Intentamos demostrar que solo podemos aproximarnos a las ideas de Plutarco sobre su oratoria si establecemos la selección que hace de los datos procedentes de otros autores y los diferenciamos de las opiniones del biógrafo. Además, hemos contrastado estos datos con los que aparecen en otras fuentes históricas y literarias. De ese análisis complejo y detallado, situado en varios niveles, podemos extraer información muy útil para el estudio de la oratoria en las biografías de Plutarco, que a veces queda desdibujada o malinterpretada cuando se enfoca en un único personaje. Queda claro que Plutarco concede mayor importancia a la conducta y el carácter de los personajes y se basa en ellos para juzgar su oratoria, distanciándose así de las valoraciones que encuentra en sus fuentes.

Palabras clave: Vidas paralelas de Plutarco; oratoria; Demóstenes; Foción; Démades.

\section{[en] Plutarch, two Lives, three orators: Phocion, Demosthenes and Demades}

Abstract. In this article the figures of the orators Phocion, Demosthenes and Demades are analysed through the biographies that Plutarch devoted to the first two personages. We try to prove that we can only approach Plutarch's ideas on their oratory if we take his selection of the data from other authors and we contrast them with the biographer's opinion. In addition, we have compared these data with what is encompassed in other historical and literary sources. From this detailed and complex analysis done at different levels we can extract very useful information. This will allow us to study the oratory in the biographies of Plutarch, wich might sometimes be blurred or misinterpreted when it is focused on just one personage. It is clear that Plutarch gives more importance to the personages' conduct and character and relies on that to judge their oratory. Thus he departs himself from the assessments that he finds in his sources.

Keywords: Plutarch's Parallel Lives; oratory; Demosthenes; Phocion; Demades.

Cómo citar: Alcalde Martín, C. (2017) Plutarco, dos Vidas, tres oradores: Foción, Demóstenes y Démades, en Cuadernos de Filología Clásica. Estudios griegos e indoeuropeos 27, 133-146.

1 Universidad de Málaga.

E-mail: cama@uma.es 
No hay que descuidar en absoluto el encanto y la eficacia de la palabra, por depositar toda la confianza en la virtud ... la retórica no es artífice de la persuación, pero ayuda a conseguirla ... pues persuaden tanto el carácter como la palabra (Praec. ger. reip., $801 \mathrm{C})$.

La oratoria del hombre de Estado no debe ser un alarde de habilidad técnica y sofisticación producto del estudio, sino que

debe estar llena de carácter sincero, sentimiento verdadero, franqueza heredada de los antepasados, previsión y solícita comprensión, y debe añadir a su nobleza el encanto y atractivo derivados de una expresión grave y unos pensamientos originales y convincentes (Praec. ger. reip., 802 E).

Sirvan estos dos pasajes de los Consejos políticos, esa «biografía ideal» de hombre de Estado, como punto de partida para el examen de la caracterización y comparación que hace Plutarco de la oratoria de tres políticos que ejercieron su actividad pública en la segunda mitad del siglo IV: Foción y Demóstenes, a quienes dedica sendas Vidas, y Démades, que no tiene una biografía con su nombre pero de quien podría hacerse una a partir de las numerosas citas en las Vidas y en Moralia; sería, eso sí, menos detallada y completa y, sobre todo, menos ejemplar ${ }^{2}$.

Podemos anticipar ya que el estudio de la oratoria no es el objetivo primordial del biógrafo, ni siquiera en el caso de un orador como Demóstenes; trata de ella solo como parte de la caracterización del hombre de Estado ${ }^{3}$.

Foción, según lo presenta Plutarco en su biografía, es el político cuya oratoria coincide más con los principios de Consejos políticos citados al principio. Es también, de los estadistas de su tiempo, el que hace una mejor elección: mientras

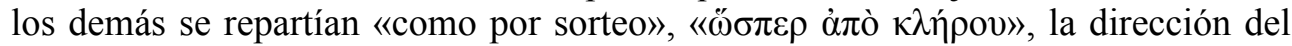
ejército y la tribuna de oradores, Foción quiso reunir ambas facetas en su actividad pública, y seguir así la política de Pericles, Aristides y Solón (Phoc. 7.5) ${ }^{4}$.

No se ha conservado ningún discurso de Foción ni citas que procedan con seguridad de alguno de ellos. Tampoco los autores antiguos se refieren a él como orador $^{5}$ y no es mencionado en el tratado Sobre el estilo de Demetrio. Para este aspecto de la actividad de Foción Plutarco es nuestra única fuente, y debemos decir

2 Dos estudios recientes tratan de ofrecer una imagen global del personaje histórico usando las fuentes de forma crítica. Basándose solo en Plutarco, Colonnese (2007: 61-78) presenta un estudio del personaje basándose solo en Plutarco, por lo que titula así el capítulo IV de su libro: «Un relitto del naufragio di Atene (Phoc. 1,3): Demade». Brun (2000) se ocupa de Démades con mayor amplitud y profundidad, basándose en todas las fuentes literarias, históricas y epigráficas, pero con tendencia a negar o minimizar los rasgos negativos de la tradición literaria y a ofrecer una imagen muy positiva del personaje.

3 Al comienzo de la Vida de Demóstenes, Plutarco renuncia a comparar su oratoria con la de Cicerón y dice que se va a centrar en lo que verdaderamente le importa y es el objetivo de todas sus biografías, el examen de los hechos que revelan el carácter de los personajes (Dem. 3.1): «Debemos examinar el carácter y las actitudes de ambos a partir de su conducta y su actividad política; en cambio, de comparar sus discursos o declarar cuál de los dos es el orador más agradable o más eficaz, es mejor que no nos ocupemos». Los biógrafos helenísticos se ocuparon más de Demóstenes como orador, y antes de Plutarco no se le trató como una figura esencialmente política: cf. Cooper (2000: 224).

4 La biografía confronta repetidamente a Foción con los que solo eran oradores, denominados «oi $\rho \dot{\eta} \tau o \rho \varepsilon \varsigma »$ y caracterizados negativamente como demagogos y corruptos: cf. e.g. Phoc. 13.7, 14.3, 21.3, 23.3.

5 Salvo implícitamente: e. g. D.S. 17.15.2. 
que poco fiable pues el deseo de engrandecer a su admirado héroe prima sobre el rigor histórico ${ }^{6}$.

La imagen del Foción orador que nos ofrece Plutarco es muy acorde con sus gustos. Proceder de clase social acomodada le permitió tener una formación intelectual adecuada para su actividad como gobernante y para el desarrollo de su oratoria: estudió en la Academia con Platón y después tuvo relación con Jenócrates (Phoc. 4.1-2).

$\mathrm{Su}$ aspecto, muy posiblemente el que percibían los ciudadanos atenienses cuando tomaba la palabra en la asamblea, estaba en consonancia con su oratoria: austero, sobrio, adusto. Nadie lo vio nunca reír ni llorar ni con la mano fuera del manto si alguna vez lo llevaba (Phoc. 4.4) ${ }^{7}$. La expresión de su rostro contradice su carácter:

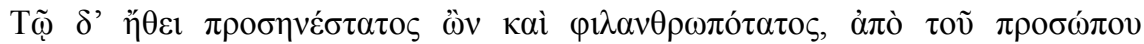

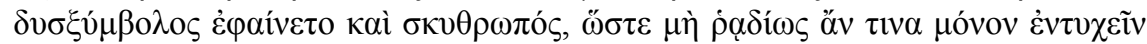

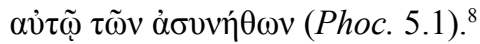

Aunque era de carácter muy agradable y humano, por el rostro parecía tan insociable y hosco que era difícil que fuera a hablarle a solas alguien si no era familiar suyo?.

Debía de tener el ceño fruncido habitualmente, pues el general Cares hizo reír a los atenienses bromeando sobre ello, a lo que Foción replicó diciendo que su ceño nunca había causado mal a nadie, pero que la risa de los otros había hecho mucho daño a la ciudad (Phoc. 5.1-2).

Por asociación de ideas Plutarco hace seguidamente la caracterización de la oratoria de Foción (Phoc. 5.3-10) transfiriéndole el mismo contraste entre apariencia y fondo:

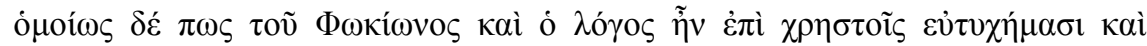

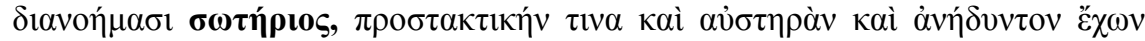

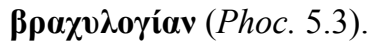

De modo semejante, también la oratoria de Foción era beneficiosa por sus hallazgos y pensamientos de provecho y tenía una concisión imperiosa, severa y áspera.

Por tanto, dos son los rasgos fundamentales de su oratoria, recogidos por los términos $\sigma \omega \tau \eta \dot{\rho}$

6 Sin embargo, Tritle (1988: 22-27) se detiene en el examen de la oratoria de Foción aceptando sin reservas la caracterización de la misma que hace Plutarco y comenta las fuentes del biógrafo.

7 Recuerda algunas de las cualidades de Pericles, con quien ya hemos visto que se le compara (Per. 5.1): su rostro era inaccesible a la risa y su manto no se agitaba con la emoción del discurso.

8 Las citas en griego, tanto de la Vida de Foción como de la Vida de Demóstenes, proceden de las respectivas ediciones de Flacelière - Chambry (1976).

9 Según Frazier (2016: 315), este contraste entre carácter y rostro es excepcional en las Vidas. Duff (1999: 145-7), observa que Plutarco, al caracterizar a Foción en diversos pasajes de la biografía, habitualmente menciona juntos rasgos en apariencia contradictorios. Para Nikolaidis (2009: 279-284), la «sociabilidad», noción incluida

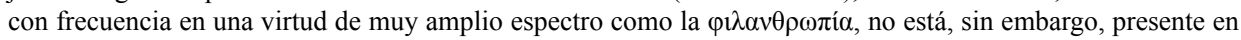
algunos personajes cuya $\varphi \imath \lambda \alpha v \theta \rho \omega \pi i ́ \alpha$ admira Plutarco: Foción, Catón el Joven y Pericles entre otros. 
de $\sigma \omega \tau \eta ́ p ı s$, pero está claro que el efecto beneficioso y salvífico para los ciudadanos

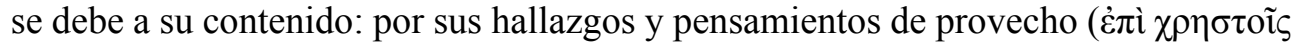

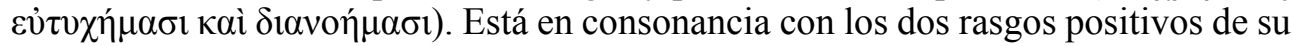
carácter que hemos mencionado antes, $\pi \rho 0 \sigma \eta v \varepsilon ́ \sigma \tau \alpha \tau o \varsigma$ y $\varphi \imath \lambda \alpha v \theta \rho \omega \pi$ ó $\alpha \alpha \tau o \varsigma$, y con el

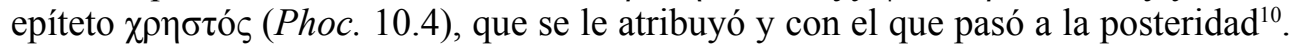
El contraste con este contenido salutífero es la concisión, calificada como imperiosa,

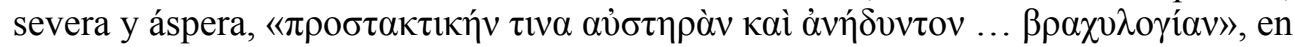
claro paralelismo con el aspecto insociable y hosco del rostro.

En cuanto a la $\beta \rho \alpha \chi \lambda \lambda_{0} \gamma_{i} \alpha$ o concisión, es un rasgo propio de un filósofo ${ }^{11}$ :

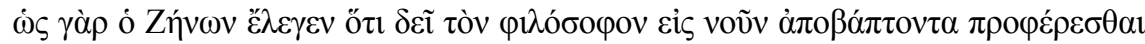

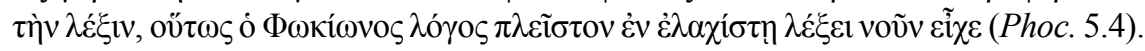

Lo mismo que Zenón decía que el filósofo debe proclamar su palabra impregnándola de sentido, así la oratoria de Foción tenía muchísimo sentido en una brevísima dicción.

Por tener en cuenta esto último, cree Plutarco, Polieucto de Esfeto consideraba

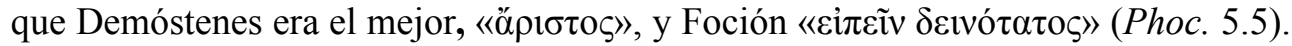

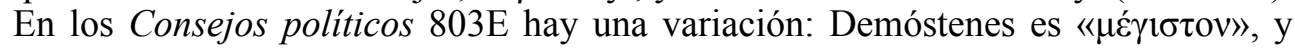

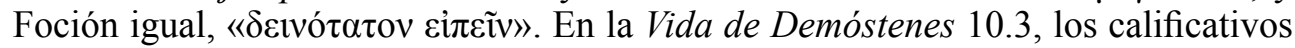

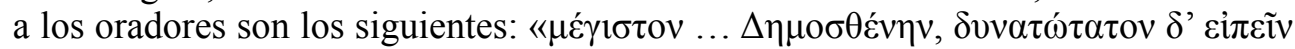

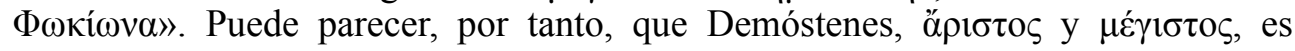
superior a Foción. Pero Plutarco solo ha citado la opinión de Polieucto.

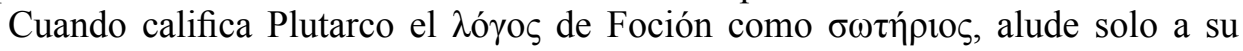
contenido. En cambio, alude a la combinación de forma y contenido cuando dice que

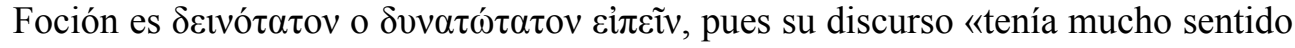
en una breve dicción».

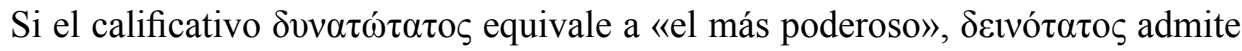
diversos significados. Referido a un estilo oratorio, el adjetivo $\delta \varepsilon ı$ ó $\varsigma$ puede tener un sentido muy cercano a $\delta v v \alpha \tau o ́ c: ~ « v i g o r o s o$, apasionado, vehemente» ${ }^{12}$.

Otro valor de $\delta \varepsilon v v o ́ \varsigma$ en el campo de la oratoria es el de «hábil» ${ }^{13}$, con sentido

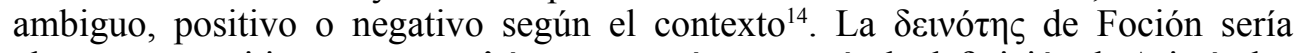
claramente positiva, ya que su $\lambda o ́ \gamma o \varsigma$ es $\sigma \omega \tau$ tŕpıs, según la definición de Aristóteles en la Ética a Nicómaco:

10 Sobre la asociación de estos términos en Plutarco, cf. Bucher-Isler (1972: 20, 36).

11 Plutarco tiene mucho interés en presentar a Foción con los rasgos de un filósofo, sobre todo los que lo asemejan a Sócrates: su aspecto (Phoc. 4.4), su justificación de un acto contrario a los intereses de Atenas (Phoc. 32.6) y su muerte $(36-37.2 ; 38.5)$. La concisión es también un rasgo propio de los lacedemonios y en Garr. 510E, Plutarco cita el elogio de Platón (Prot. 342e) a la concisa dicción de los espartanos. Cf. también Demetr.

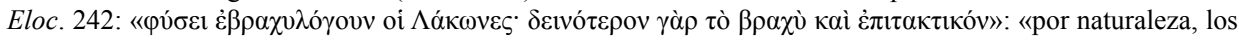
lacedemonios hablaban con concisión, pues lo conciso es más vigoroso y autoritario».

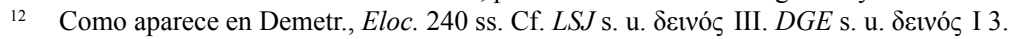

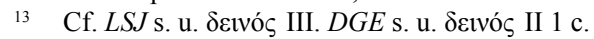

14 Ambiguo es, e incluso negativo, determinado por $\lambda \varepsilon \dot{\gamma \varepsilon \iota v}$ en S., OT 545 y en E., Med. 585; y determinado por

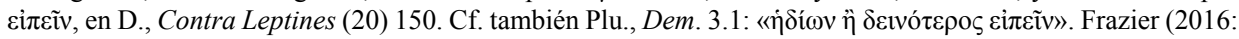
284-6), partiendo de Arist., EN 6.12.1144 a, hace un excelente análisis de la $\delta \varepsilon \imath$ ó $\tau \varsigma$ referida a la oratoria y enumera pasajes de las Vidas de Plutarco en los que aparece con significados positivos o ambiguos. 


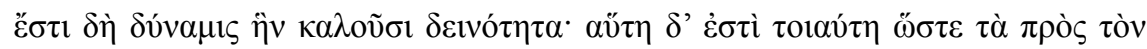

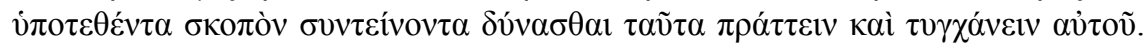

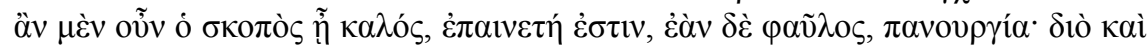

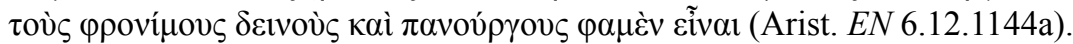

Hay una facultad que llaman habilidad, y es tal como para que uno pueda realizar las acciones que tienden al objetivo propuesto $-\mathrm{y}$ conseguirlo- - Pues bien, si el objetivo es bueno, será elogiable, pero si es malo, será habilidad para el mal. Por eso llamamos hábiles tanto a los prudentes como a los malhechores ${ }^{15}$.

Posiblemente, la cita de Polieucto provenga de Teofrasto ${ }^{16}$, como puede dedu-

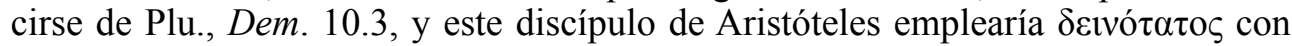
el sentido de «el más hábil» ${ }^{17}$. Pero lo más probable es que Plutarco entendiera el término, en la Vida de Foción y en los Consejos políticos, con el sentido de «el más vigoroso», que le daban los retóricos posteriores como Demetrio, y por eso en la Vida de Demóstenes (10.3) lo cambia por $\delta v v \alpha \tau \omega ́ \tau \alpha \tau o v$ y explica ambos términos de la misma manera: condensan el mayor sentido en la expresión más breve. En la Vida de Foción se sirve de una comparación:

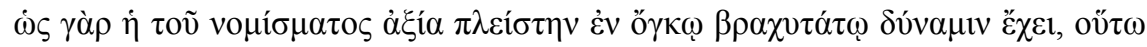

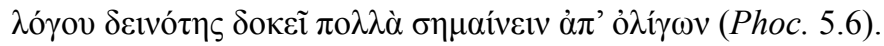

Así como el mérito de la moneda es tener el mayor valor en el menor volumen posible, igualmente la fuerza de un discurso parece que consiste en ofrecer mucho significado con pocas palabras ${ }^{18}$.

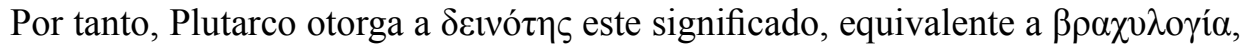
de manera específica para Foción ${ }^{19}$.

Seguidamente, ilustra el afán de concisión de Foción mediante una $\chi \rho \varepsilon i ́ \alpha$ :

En cierta ocasión, mientras se llenaba el teatro, paseaba al pie de la escena ensimismado en sus pensamientos y uno de sus amigos le dijo: «Foción, parece que estás meditabundo», y él le contestó: «Sí, por Zeus, medito si puedo quitar algo del discurso que voy a pronunciar ante los atenienses» (Phoc. 5.7-8)20.

Queda un último significado del adjetivo $\delta \varepsilon v$ ó $\alpha \tau$ ç que no sería usual en un contexto de retórica pero que, igual que los citados anteriormente, debemos tener en

15 Trad. de Calvo Martínez (2001).

16 Cf. Tritle (1988: 23) y Cooper (2000: 227).

17 Cf. Tritle (1988: 24-25): «It does not mean that Phocion was a more forceful speaker than Demosthenes, but rather that he was a more clever orator ... an ability to destroy arguments by clever counter-arguments rather than an ability to speak more forcefully».

18 Plutarco usa también la comparación con la moneda (aunque de modo diferente) para iluminar la concisa dicción de los espartanos: cf. Plu., Lyc. 19.1-2.

19 La asociación de los términos $\beta \rho \alpha \chi u ́ \varsigma$ y $\delta \varepsilon v$ ó $\varsigma$ se encuentra también en Demetr. Eloc., 242: cf. la cita en nota 11. Pero Plutarco especifica que la concisión o $\beta \rho \alpha \chi \nu \lambda o \gamma i ́ \alpha$ «consiste en ofrecer mucho significado con pocas palabras».

20 De manera similar, Pericles, cuando se dirigía a la asamblea, rogaba a los dioses que no se le ocurriera ninguna palabra ajena al tema que había de tratar: Plu., Per. 8.6. 
cuenta aquí, el de «terrible» o «temible» ${ }^{21}$ para sus adversarios en el debate político. Y así debía de ser para Demóstenes, si son ciertas las palabras que Plutarco le atribuye:

Demóstenes sentía un gran desprecio por los demás oradores, pero cuando Foción se levantaba, solía decir susurrando a sus amigos: «Aquí está el hacha de mis

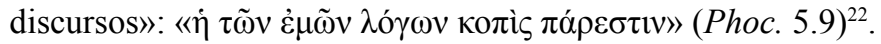

La interpretación que da Plutarco a estas palabras de Demóstenes es indicativa de la importancia secundaria que concede a la retórica:

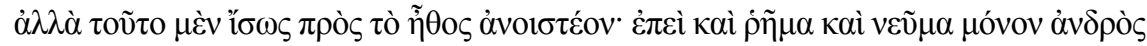

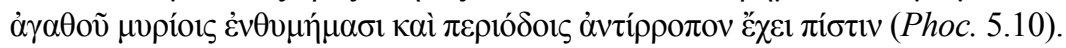

Quizás haya que atribuir esto a su carácter, puesto que una sola palabra y señal con la cabeza de un hombre bueno inspiran igual grado de confianza que innumerables razonamientos y períodos.

Queda claro en este balance final que la oratoria de Foción supera a la de Demóstenes, pero, más que por sus cualidades como orador, por su carácter, pues una palabra o gesto suyos equivalen o son superiores al despliegue de habilidad técnica del otro ${ }^{23}$.

Una conclusión importante que podemos extraer del relato de Plutarco es que no se interesa por la retórica en sí, sino por cómo esta es adecuada para la finalidad política del orador y cómo, a través de la coincidencia con su carácter —el acoplamiento de la oratoria de Foción con su carácter y su actuación pública y privada es total—, se puede llegar al conocimiento de este.

En la Vida de Demóstenes, Plutarco suministra mucha información sobre la oratoria del protagonista, entrelazando datos y opiniones sobre él de otros oradores y escritores, unas positivas y otras negativas.

La $\pi \rho \circ \alpha i ́ p \varepsilon \sigma ı \varsigma$ o vocación de entrar en la vida pública va unida a su actividad como orador:

entrenado en los discursos a causa de su herencia ... por el sabor de la ambición y poder que producen los debates (Dem. 6.1).

Plutarco va a explicar la falta de cualidades naturales de Demóstenes (Dem. 6.3-5) y los grandes esfuerzos y entrenamientos que realiza para superarla; además pone de relieve la importancia que concedía a la forma y la actuación, tomando consejo incluso del actor Sátiro ${ }^{24}$ (Dem. 7.1-8.2). En consecuencia (Dem. 8.3), adquirió fama

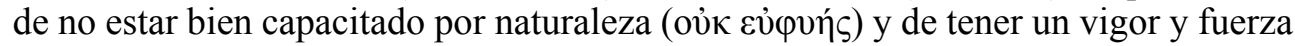

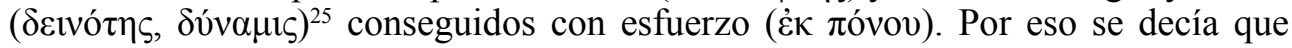

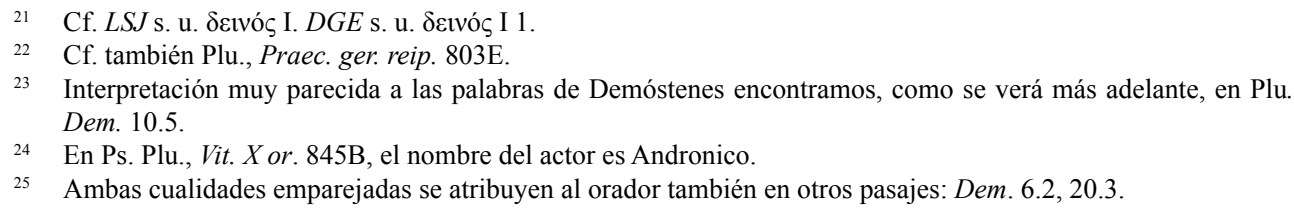


tenía dificultad para improvisar ${ }^{26}$, y se tomaba como prueba de ello que Démades se levantó muchas veces para hablar en defensa de Demóstenes cuando lo abucheaban pero que Demóstenes nunca hizo lo mismo por él (Dem. 8.7). Pero Plutarco aporta ejemplos con los que demuestra que Demóstenes sí tenía capacidad para improvisar (Dem. 9.1). Es conocida sobre todo la anécdota de Piteas, que le dijo en son de burla que sus razonamientos olían a mecha de lámpara, y Demóstenes le replicó: «no son testigos de las mismas intimidades mi lámpara y la tuya» (Dem. 8.4-5).

Cuando llega la comparación explícita con Démades (Dem. 10.1-2), Plutarco ofrece dos informaciones: la primera, que, según la opinión general de sus contemporáneos, Démades era invencible por sus cualidades naturales y sus improvisaciones superaban las meditadas elaboraciones de Demóstenes. Pero tal opinión ya aparece contrarrestada por las pruebas de la capacidad de Demóstenes para improvisar que Plutarco, como hemos visto, ha contado en el capítulo precedente. La segunda es la opinión de Teofrasto, que no es muy sorprendente por tratarse de un peripatético y promacedonio: preguntado acerca de Demóstenes como orador, respondió que «digno de la ciudad», y acerca de Démades contestó: «por encima de la ciudad» ${ }^{27}$. En esta comparación ventajosa para Démades, se limita Plutarco a contar lo que ha leído pero sin insistir en ello.

A la comparación con Démades, sigue la comparación, que ya hemos visto anteriormente, con Foción (Dem. 10.3-4), de quien Demóstenes decía que era el hacha de sus discursos. Plutarco comenta estas palabras de Demóstenes de la siguiente manera:

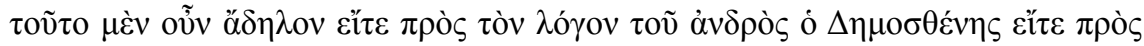

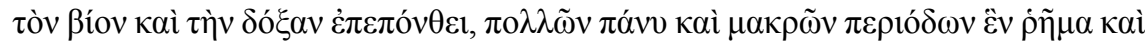

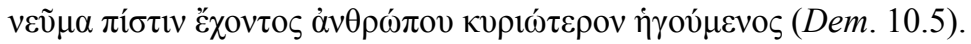

No está claro si Demóstenes experimentaba este sentimiento por la oratoria del personaje o por su vida y su reputación, al considerar que una sola palabra o movimiento de cabeza de un hombre que inspira confianza (i.e. Foción) tiene más influencia que innumerables y largos períodos (i.e. los discursos de Demóstenes).

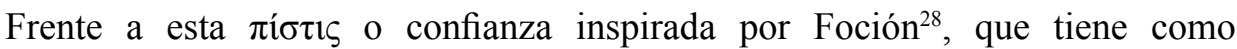
fundamento su carácter reflejado en su concisión llena de sentido, la $\pi i ́ \sigma \tau 1 \zeta$ que

26 Sobre esta posible dificultad de Demóstenes, así como de sus entrenamientos para superar sus deficiencias naturales y de la importancia que concedía a la actuación, cf. el resumen en Worthington (2013: 38-41). McDowell (2009: 5-7, 21) encuentra indicios de la dificultad para improvisar en los discursos conservados de Demóstenes, pero duda de la veracidad de todas las anécdotas transmitidas. Más crítico es Cooper (2000), que atribuye a los intereses filosóficos y políticos de los peripatéticos contemporáneos de Demóstenes la creación y/o difusión de las opiniones negativas sobre su oratoria.

27 El elogio de Teofrasto no solo tendría motivaciones políticas, sino que también se debería a la capacidad del orador para improvisar, muy apreciada por los peripatéticos como muestra de las cualidades naturales: cf. Marzi (1991: 79-80); Cooper (2000: 225-229). Brun (2000: 18-30) analiza los distintos testimonios sobre la oratoria de Démades, tanto de contemporáneos suyos como de otros autores griegos y latinos; afirma Brun, con razón, que Démades fue un gran orador (p. 30), pero exagera al concluir de la frase de Teofrasto, sin tener en cuenta su posible tendenciosidad, que (p. 18) «semble indiquer que l' on voyait en lui le meilleur orateur de son temps».

28 Sin embargo, los discursos de Foción no solían tener aceptación en la asamblea, como se verá más adelante. Hay además cierta contradicción entre este pasaje (y también Phoc. 5.10) con el comienzo de la Vida de Foción 1.4-6, donde leemos que su virtud se enfrentó a una fortuna adversa, para Grecia y para él mismo, lo que pudo debilitar la confianza en ella. Cf. el estudio de este pasaje en Leâo (2010: 186-8) y Fialho (2010: 198-200). 
busca Demóstenes carece de sinceridad pues intenta conseguirla mediante el

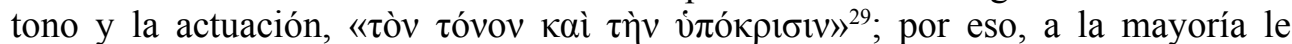
encantaba cuando actuaba («نं comparando así a Demóstenes con un actor de teatro; de hecho, ya lo hemos visto, había recibido enseñanzas de $u^{30}{ }^{30}$ ). Pero las personas refinadas, como Demetrio de Falero (otra vez un testimonio negativo para Demóstenes proveniente de un

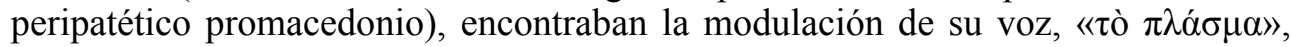
vulgar, chabacana y blandengue (Dem. 11.3).

Recordemos aquí algunos de los principios expuestos en los Consejos políticos citados al comienzo de este trabajo: la oratoria del hombre de Estado no debe ser un alarde de habilidad técnica y sofisticación y fluidez estilística producto del estudio, sino que «debe estar llena de carácter sincero, sentimiento verdadero, franqueza, etc.» Bastante lejos de estos principios parece que se encuentra la estudiada retórica

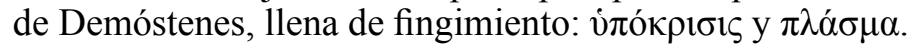

Hasta aquí, en esta descripción de la oratoria de Demóstenes en la que se van entrelazando distintas opiniones de contemporáneos suyos y algunos juicios del propio Plutarco, han ido alternando rasgos positivos y negativos con predominio de estos últimos, de manera que Demóstenes queda por debajo de Foción ${ }^{31}$. Pero, seguidamente, Plutarco va a destacar los positivos para situar a Demóstenes por encima de los demás oradores ${ }^{32}$.

Esión decía de los discursos de Demóstenes que, al leerlos, superaban a los de

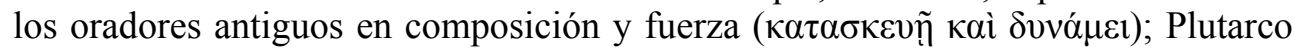

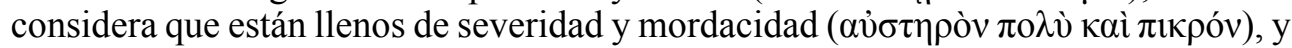
que además también se servía de la chanza en las contestaciones improvisadas (Dem. 11.4-5). De los ejemplos presentados, uno tiene especial relevancia:

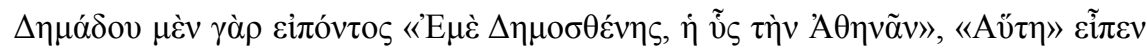

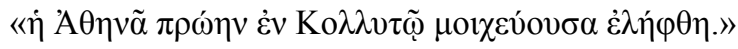

Cuando Démades dijo: «¡Conmigo va a competir Demóstenes! La cerda con Atenea», replicó: «Esa Atenea fue sorprendida hace poco en Colito cometiendo adulterio».

Los contemporáneos de Démades, dice Plutarco, pensaban que era invencible en la improvisación, pero el biógrafo no da ningún ejemplo de esa capacidad ni en la Vida de Foción ni en la de Demóstenes. Por el contrario, ofrece varios ejemplos de la improvisación de Demóstenes (al que se tenía por poco hábil para la misma), y en el que acabamos de ver no solo vence dialécticamente a Démades, sino que además muestra la corrupción moral de este en la vida privada. Plutarco pasa así de la técnica

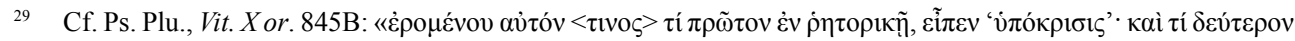

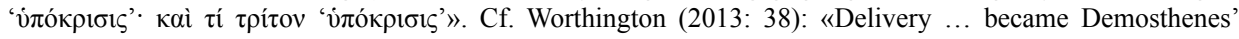
principal stylistic feature».

30 Aspecto señalado por Mossman (1999: 87).

31 Subraya Cooper (2000: 225-229, 232-234) que son de procedencia peripatética (en especial de Demetrio de Falero) tanto los juicios negativos sobre Demóstenes y su gusto por la actuación teatral (que conlleva implícita la corrupción moral del orador) como el juicio favorable de la oratoria de Foción junto a la tradición de su integridad moral.

32 Mossman (1999: 83-89) hace un perspicaz análisis de las contraposiciones de elementos negativos y positivos que caracterizan la oratoria de Demóstenes en la Vida de Plutarco. 
oratoria al plano de los hechos y el modo de vida y, sin decirlo explícitamente, invalida los testimonios favorables a Démades.

Lo mismo que en el caso de Foción con respecto a Demóstenes, la superioridad de este con respecto a Démades se hace también patente y definitiva en su actuación política: Demóstenes tomó como noble base de su política la defensa de los griegos contra Filipo, y así muy pronto adquirió notoriedad por la franqueza de sus discursos y fue admirado dentro y fuera de Grecia (Dem. 12.7). Esta posición política en la que se situó al principio la mantuvo siempre, e incluso entregó su vida por no cambiar. No era como Démades y otros, que daban bandazos según los intereses del momento (Dem. 13.2-4) ${ }^{33}$.

Sigue Plutarco elogiando los discursos de Demóstenes por su contenido, y en concreto su actitud antidemagógica, diciendo que en ellos no concede a los ciudadanos lo más agradable, fácil o provechoso, por considerar que se debe buscar ante todo el bien y lo conveniente. Una restricción hay en el balance positivo de Demóstenes como orador, de nuevo su conducta privada (posible alusión a su venalidad) y, sobre todo, pública ${ }^{34}$ :

Si a la ambición de sus principios y a la nobleza de sus discursos se hubieran añadido el valor guerrero y un comportamiento siempre intachable, merecería figurar no en la relación de los oradores como Merocles, Polieucto e Hiperides, sino en otra superior, junto a Cimón, Tucídides y Pericles (Dem. 13.6).

Por el contrario,

Foción, a pesar de que propugnaba una política que no cosechaba aplausos, pues se le consideraba partidario de los macedonios, sin embargo, debido a su valor y su justicia no fue considerado en absoluto inferior a Efialtes, Aristides y Cimón (Dem. 14.1).

Concluye el juicio de Plutarco sobre la oratoria de Demóstenes emparejándola con su vida, diciendo que

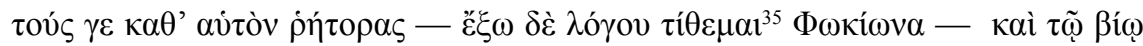
$\pi \alpha \rho \tilde{\eta} \lambda \theta \varepsilon$ (Dem. 14.3).

a los oradores de su tiempo — hago excepción de Foción — los aventajó incluso en su modo de vida.

Encontramos, pues, algunas reservas en la Vida de Demóstenes cuando Plutarco valora al orador; sin embargo, cuando no tiene que compararlo con Foción, parece

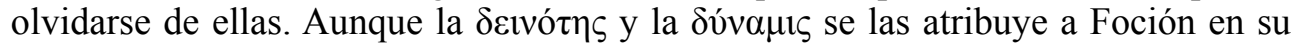

33 Sobre esta acusación de Plutarco a Démades, y las posibles motivaciones históricas, cf. Colonnese (2007: 66-68).

34 Plutarco insiste en la Vida de Demóstenes en la confrontación entre oratoria y hechos, y en la mayor importancia de estos últimos. Sobre ello, cf. Mossman (1999: 82-89).

35 El uso de la primera persona deja claro que es Plutarco, con independencia de sus fuentes, quien sitúa a Foción en primer lugar entre los oradores de su tiempo. 
más alto grado, resalta también ambas cualidades en Demóstenes ${ }^{36}$. Un pasaje muy significativo, por la valoración de Demóstenes como orador y a la vez como político, es la narración de los pensamientos de Filipo II de Macedonia después de la victoria de Queronea ${ }^{37}$ :

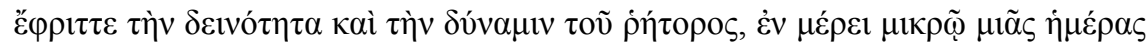

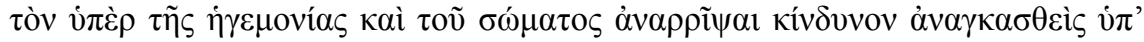

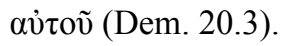

Se estremeció ante la fuerza y el poder del orador, pues se había visto obligado por él a jugarse, en una pequeña parte de un solo día, su imperio y su vida.

La valoración más positiva y elogiosa que Plutarco hace de su oratoria la encontramos al final de la Vida de Cicerón, en la Comparación de ambos, donde de nuevo resalta, junto a otras cualidades, su $\delta \varepsilon \imath$ ó $\tau\rceil s:$

Demóstenes aplicó a la oratoria toda la habilidad retórica que poseía por

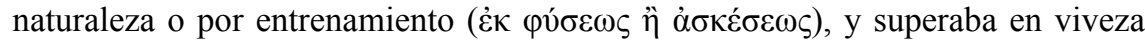

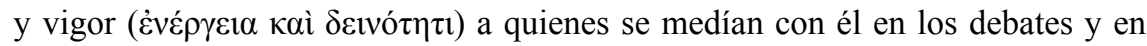
los procesos, en majestuosidad y elevación $(\mu \varepsilon \gamma \alpha \lambda \mathrm{o} \pi \rho \varepsilon \pi \varepsilon i ́ \alpha)$ a los oradores de aparato, y en precisión y destreza a los sofistas (Cic. 50 (1)).

Podemos concluir de este repaso a la comparación de los tres oradores que Plutarco, en lugar de comparar él por su cuenta la oratoria de Demóstenes con la de Foción y con la de Démades, cita las valoraciones comparativas de autores contemporáneos de los personajes, y que sus juicios personales los vierte al comentar tales comparaciones o al caracterizarlos por separado. Un motivo puede ser que no conoció ningún discurso de Démades ni Foción — solo dichos, con frecuencia descontextualizados, atribuidos a uno y otro - . Pero quizás la razón principal sea que lo que más le importa es el conocimiento del carácter y por eso sí compara la conducta y el carácter de los tres personajes, y de tal comparación extrae la valoración de su oratoria.

En cuanto a Démades, ya hemos visto que su oratoria ${ }^{38}$ se compara solo con la de Demóstenes y que Plutarco se basa sobre todo, para contrarrestar la opinión de quienes lo consideraban invencible y superior, en su mudable conducta política. A esto se añade su corrupción: aceptó interceder por los oradores atenienses que Alejandro reclamaba cuando estos le pagaron cinco talentos (Dem. 23.6). La inconstancia de sus posiciones políticas, llegando hasta la traición, será la causa de su muerte ignominiosa y violenta en Macedonia, acusado de traición por Casandro.

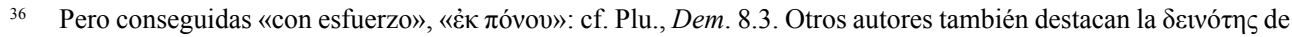
Demóstenes: cf. D. H., Is., 20, que la considera la más acabada forma de oratoria. Demetr. Eloc. ilustra el estilo

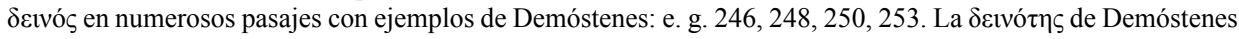
se debería no solo a las figuras de estilo empleadas, sino también a la actuación o representación: cf. Cooper (2000: 230), que se apoya en Demetr. Eloc. 271. Cf. también MacDowell (2009: 407).

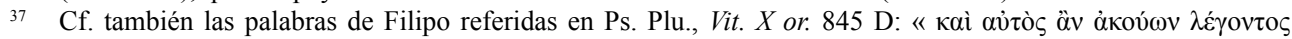

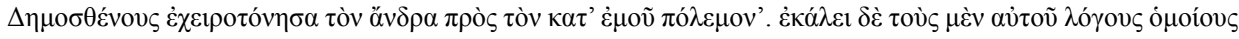

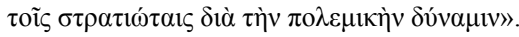

38 Ningún discurso auténtico se ha conservado de él. El discurso Sobre los doce años no se le puede atribuir: cf. Worthington (1991). Ya en la propia Antigüedad se constataba que no se habían transmitido discursos suyos: cf. Cic., Brutus 9.36; Quint. 2.17.13, 12.10.49. 
Con este episodio acaba la Vida de Demóstenes (Dem. 31.4-6), en contraste con la muerte digna y heroica del protagonista previamente relatada.

El papel de antihéroe que desempeña Démades es aún más acusado en la Vida de Foción, en la que, por sus grandes defectos, tiene como única misión hacer resaltar las virtudes del héroe. Hasta el punto de que esta biografía no comienza hablando de su protagonista, sino de Démades (Phoc. 1.1-3) y destacando su inmoralidad tanto

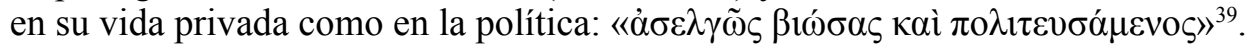

Llama la atención que no se compare la oratoria de Foción con la de Démades. Sin embargo, la capacidad retórica de este ${ }^{40}$ se deja entrever incluso en las críticas que recibe al comienzo de la Vida de Foción:

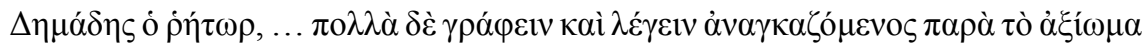

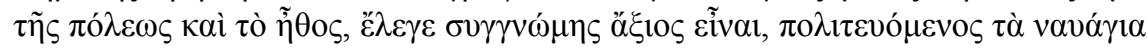
$\tau \tilde{\eta} \varsigma \pi \hat{\lambda} \varepsilon \epsilon \omega \varsigma$ (Phoc. 1.1).

El orador Démades, que ... se veía forzado a redactar y exponer muchas propuestas contrarias a la dignidad y el carácter de la ciudad, decía que merecía el perdón porque administraba los restos del naufragio del Estado.

Este ingenioso empleo de la metáfora de la nave del Estado para justificar su política puede constituir una muestra de su habilidad retórica, pero Plutarco lo vuelve contra él afirmando que el propio Démades era un resto del naufragio. También el insulto que le dirige Antípatro, quien

dijo de él, ya en su vejez, que era como una víctima sacrificada de la que solo quedaba la lengua y el vientre (Phoc. 1.1),

es un reconocimiento, junto a su corrupción, de su pericia como orador. Hay otros ejemplos de su diestro manejo de las figuras retóricas también en la Vida de Foción. Cuando llegó a Atenas la noticia de la muerte de Alejandro, Démades y Foción intentaron evitar una revuelta popular. Foción con palabras muy sensatas:

Si hoy está muerto, también lo estará mañana y pasado mañana, de modo que podemos deliberar con tranquilidad y, sobre todo, con seguridad (Phoc. 22.5).

Démades aconsejaba no hacer caso de la noticia con una brillante hipérbole:

De ser así, el mundo entero debería estar oliendo a cadáver desde hacía tiempo (Phoc. 22.6).

¿Formarían estas dos citas parte de sus respectivos discursos en la asamblea?

39 Cf. Colonnese (2007: 69-70). Alcalde-Martín (2008: 28-30).

40 Brun (2000: 18-31) señala que es reconocida por autores contemporáneos y por historiadores como Diodoro. La atribución de máximas conocidas como $\delta \eta \mu \alpha ́ \delta \varepsilon ı \alpha$ prueban el reconocimiento de su habilidad retórica. Pero la tradición anecdótica, recogida por Plutarco y centrada en su vida corrupta, creó una «leyenda negra» sobe Démades. 
La traición a Antípatro, causa de la muerte de Démades, fue descubierta por una carta suya dirigida a Antígono que había sido interceptada ${ }^{41}$. En ella le pedía que fuera a ponerse al frente de Macedonia y Grecia y aludía a Antípatro con esta metáfora:

Los griegos y macedonios están pendientes de un hilo viejo y podrido (Phoc. 30.9).

Si Démades es citado en la Vida de Demóstenes como maestro de la improvisación, también en este aspecto puede superarlo Foción:

Démades le dijo: «Foción, ¿por qué no convencemos a los atenienses de que adopten el régimen laconio? Si tú me lo pides, yo estoy dispuesto a redactar y proponer el decreto». «Desde luego te quedaría muy bien a ti», le respondió Foción, «tan perfumado de mirra y con una clámide como la que llevas, aconsejar a los atenienses las comidas en común y elogiar a Licurgo» (Phoc. 20.6).

La anécdota muestra dos cosas: la mudable política de Démades y el lujo y la corrupción de su vida privada.

La actitud de Plutarco es diferente cuando su objetivo no es comparar a Démades con Demóstenes ni con Foción y puede llegar a reconocerle algún mérito. En los Consejos políticos dice que, en el discurso político, las metáforas producen la mayor impresión si se les da un empleo moderado y oportuno, y cita la de los restos del naufragio del Estado (Praec. ger. reip. 803A). En otro pasaje, pone a Démades como ejemplo de dirigente que sabe desviar los deseos del pueblo hacia lo más conveniente: evitó que los atenienses se rebelaran contra Alejandro proponiéndoles una distribución de dinero en lugar de emplearlo en equipar trirremes (Praec. ger. reip. 818E) ${ }^{42}$.

La parcialidad de Plutarco, empeñado en presentar casi siempre a Démades como un personaje negativo, permite solo entrever sus cualidades como orador. Otros autores, sin embargo, no dudan en reconocerlas. Así, Demetrio dedica un apartado amplio (Eloc. 282-286) a los dichos de Démades (conocidos como $\delta \eta \mu \alpha ́ \delta \varepsilon 1 \alpha$ ) para

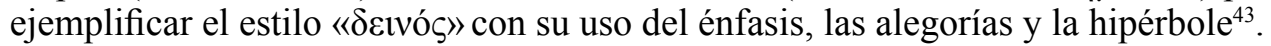

Puede ser ilustrativo para la comparación que analizamos si nos detenemos brevemente en un pasaje de Diodoro (17.15.3-5) que relata la reacción ateniense a la exigencia del rey Alejandro, después de la destrucción de Tebas, de que le entregasen a sus enemigos políticos. Dejando aparte otras cuestiones, fijaremos nuestra atención solo en las similitudes y diferencias con Plutarco en relación con la oratoria de los tres políticos que nos ocupan:

Tras muchos discursos en la asamblea, Foción se mostró partidario de que se entregaran voluntariamente los personajes reclamados por Alejandro, entre los que

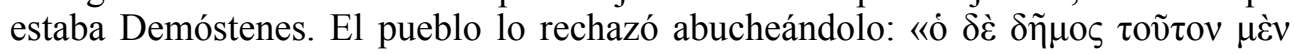

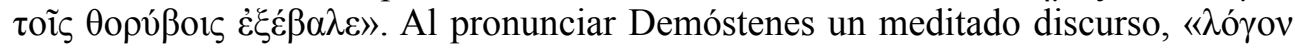

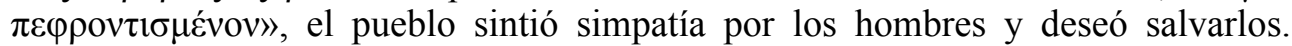
Finalmente Démades, sobornado por Demóstenes, aconsejó su salvación y presentó

41 En Plu., Dem. 31.5 y Diod. 18.48.2, el destinatario de la carta es Pérdicas. La mención a Antígono en la Vida de Foción debe de ser un error de Plutarco.

42 Cuando Agis III de Esparta se rebeló contra Alejandro en el 333, Démades contuvo al pueblo ateniense para evitar que se adhiriese a la sublevación. Demóstenes también se mostró partidario de la neutralidad. Cf. Plu. Dem. 24.1. Cf. Lingua (1978: 34). Brun (2000: 85-89).

43 Sobre su genialidad oratoria, manifestada en las metáforas y otras figuras de estilo, cf. Marzi (1991: 81). 


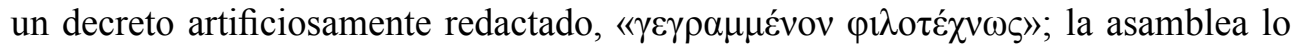
aprobó y despachó a Démades, junto con otros, como embajador ante Alejandro.

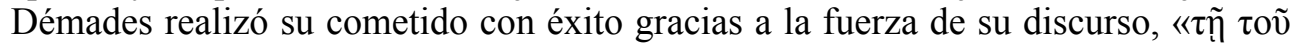

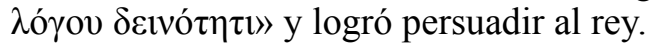

La imagen de los tres oradores que encontramos en Diodoro no es, ciertamente, la que Plutarco desea y se esfuerza en transmitir en sus biografías. Sobre todo, porque Foción es el que lleva la peor parte y Démades la mejor. Por eso en la Vida de Foción (17.2-6) y la de Demóstenes (23.6), Plutarco da una versión muy diferente de este episodio, omitiendo o relegando a Démades y atribuyendo a Foción todo el mérito del acuerdo con Alejandro. ${ }^{44}$

Pero lo cierto es que esa semblanza de los oradores ofrecida por Diodoro concuerda con la que da Plutarco, en unos casos explícitamente y en otros sin proponérselo. Que los discursos de Demóstenes eran meditados y solía ganar el afecto del pueblo, es algo que Plutarco dice claramente (Dem. 8.2-7; 11.3). En la venalidad de Démades, también concuerdan Diodoro y Plutarco (Dem. 23.6); y en cuanto a su fuerza retórica y el éxito de sus discursos, Plutarco no lo dice de manera explícita pero podemos deducirlo: reconoce que las propuestas de Foción no solían ser aceptadas por el pueblo (Phoc. 8.5; Dem. 14.1) y, en cambio, da algunos ejemplos en los que se aceptan las de Démades (Phoc. 16.5-6; 30.9; Praec. ger. reip. 818E-F). Plutarco

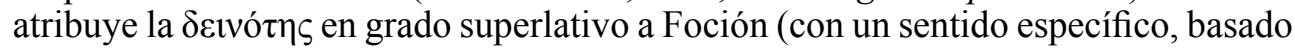
en su concisión) y también a Demóstenes, pero gracias a ella, según Diodoro, tiene éxito el discurso de Démades ante el rey. Esta cualidad, precisamente, el autor de Sobre el estilo la considera el rasgo que define los dichos de Démades (Demetr., Eloc. 282-286), y el propio Plutarco, aunque no se la atribuye explícitamente, hemos visto que ofrece ejemplos de la misma. Si añadimos a todo ello la capacidad para improvisar de Démades, esta podría ser una imagen de los oradores cercana a la que tenían sus contemporáneos; y también es la que, en parte, nos ofrece Plutarco si, además de la caracterización directa de su oratoria, tenemos en cuenta el conjunto de los datos que aparecen en las dos biografías y las leemos también entre líneas.

Podemos concluir que Plutarco concede una importancia fundamental al carácter y la conducta de los personajes como un elemento decisivo para juzgar su oratoria. Se aparta así de las valoraciones que encuentra en sus fuentes, que utiliza con sentido crítico y adaptándolas a sus propios criterios. Establece un orden de preferencias en el que Foción ocupa el primer puesto, seguido de Demóstenes. Cree que Foción era el orador más vigoroso por condensar el mayor significado en la expresión más breve, y que superaba, por la confianza que inspiraban la integridad de su carácter y de su vida pública y privada, a Demóstenes, a pesar de que algunas de sus fuentes consideraban a este último el mejor. Valora en Demóstenes, sobre todo, la constancia y firmeza de sus posiciones políticas frente a Macedonia. Sobre la oratoria de Démades, al que algunas fuentes situaban por encima de los demás, no emite un juicio personal explícito; se limita a consignar las informaciones positivas, que se esfuerza en contrarrestar con ejemplos que muestran la superioridad de los otros dos oradores y lo caracteriza en las Vidas de estos como el antihéroe que, por la depravación de su vida pública y privada, sirve de contraste a las virtudes de los

44 El relato del episodio tiene mayor verosimilitud en la Vida de Demóstenes, que coincide más con Diodoro, que en la Vida de Foción: cf. Obradovic (2012: 37). Brun (2000: 73-78) da crédito a la versión de Diodoro. Bearzot (1985: 145-149) ofrece un acertado análisis de las fuentes del acontecimiento histórico. 
protagonistas. Sin embargo, una lectura atenta de ambas biografías, y también de algunos pasajes de los Consejos políticos, deja traslucir una imagen distinta de la oratoria de los tres personajes que está más acorde con otras fuentes históricas.

\section{Bibliografía}

Alcalde-Martín, Carlos (2008), «Los personajes secundarios y su contribución al retrato del protagonista en las Vidas de Foción y Catón el Joven», en Ferreira - Stockt - Fialho (eds.), Philosophy in society. Virtues and values in Plutarch, Lovaina-Coimbra: 19-38.

Bearzot, Cintia (1985), Focione tra storia e trasfigurazione ideale, Milán.

Brun, Patrice (2000), L'orateur Démade:essai d'histoire et d'historiographie, Bordeaux.

Bucher-Isler, Barbara (1972), Norm und Individualität in den Biographien Plutarchs, BernaStuttgart.

Calvo Martínez, José Luis (2001), Aristóteles, Ética a Nicómaco, Madrid.

Colonnese, Chiara (2007), Le scelte di Plutarco. Le Vite non scritte di greci illustri, Roma.

Cooper, Craig, (2000), «Philosophers, politics, academics: Demosthenes' rhetorical reputation in Antiquity», en Worthington, Demosthenes. Statesman and orator (ed.), New York: 224-245.

$D G E=$ Diccionario Griego-Español en linea (dge.cchs.csic.es/xdge/).

Duff, Tim (1999), Plutarch's Lives. Exploring virtue and vice, Oxford.

Fialho, Maria do Céu (2010), «The interplay of textual references in Plutarch's Life of Phocion», en F. Frazier - D. F. Leâo (eds.), Tychè et Pronoia. La marche du monde selon Plutarque, Coimbra: 195-205.

Flacelière, Robert - Chambry, Émile (1976), Plutarque. Vies. Tome X. Phocion - Caton le Jeune, Paris.

- (1976), Plutarque. Vies. Tome XII. Démosthènes - Cicéron, Paris.

Frazier, Françoise (2016), Histoire et morale dans les Vies parallèles de Plutarque, Paris.

Leâo, Delfim F. (2010), «Tyche, Kairos et Chronos dans le Phocion de Plutarque», en Frazier Leâo (eds.), Tychè et Pronoia. La marche du monde selon Plutarque, Coimbra: 183-194.

Lingua, Agnese (1978), «Demostene e Demade. Trasformismo e collaborazionismo», GIF 30: 27-46.

$L S J=$ Liddel, Henry George - Scott, Robert - Jones, Henry Stuart $\left(1940^{9}\right)$, A Greek - English lexicon, Oxford.

MacDowell, Douglas (2009), Demosthenes the orator, Oxford.

Marzi, Mario (1991), «Demade, politico e oratore», Atene e Roma 36: 70-83.

Mossman, Judith (1999), «Is the pen mightier than the sword? The failure of rhetoric in Plutarch's Demosthenes», Histos 3: 77-101.

Nikolaidis, Anastasios (2009), «Philanthropia as sociability and Plutarch's unsociable heroes», en Ferreira - Leâo - Tröster - Dias (eds.), Symposion and Philanthropia in Plutarch, Coimbra: 275-288.

Obradovic, Mirko (2012), «Demades' embassies to Macedon and to the macedonians in Plutarch», Belgrade Historical Review 3: 31-43.

Tritle, Lawrence A. (1988), Phocion the good, London-New York-Sidney.

Worthington, Ian (1991), «The context of [Demades] On the twelve years», CQ 41(1): 90-95.

- (2013), Demosthenes of Athens and the fall of classical Greece, Oxford. 